\title{
Rapidly obtained ecosystem indicators from coral reef soundscapes
}

\author{
Lauren A. Freeman ${ }^{1, *}$, Simon E. Freeman ${ }^{2}$ \\ ${ }^{1}$ National Research Council Postdoctoral Fellow, Remote Sensing Division, Naval Research Laboratory, Washington, DC 20375, USA \\ ${ }^{2}$ Underwater Acoustics Division, Naval Research Laboratory, Washington, DC 20375, USA
}

\begin{abstract}
Present-day coral reef ecosystem monitoring techniques can be costly, labor-intensive point measurements that can potentially introduce intractable sampling bias and error. Here we report correlations between visually obtained ecological assessment metrics and concurrently recorded aspects of the underwater biological soundscape over coral reefs at 23 sites spanning the Hawaiian Islands archipelago. Sites from the 'cool tropics' oceanographic habitat grouped along a principal component defined by an acoustic sliding scale: from protected or more remote sites at which lower frequencies were more dominant, to degraded sites which produced soundscapes dominated by higher frequency sound. Positive correlations between ambient biological sounds below $2 \mathrm{kHz}$ and the density of benthic invertebrates (Pearson's $\rho=0.61-0.76$ ), their predators $(\rho=0.65-0.8)$, organism-scale bathymetric complexity $(\rho=0.6-0.62)$ and the quantity of crustose coralline algae ( $\rho=0.6-0.62)$ suggest a connection between this part of the spectrum, habitat complexity and the density of benthic fauna. A positive correlation was also observed between the daytime soundscape in the 2 to $20 \mathrm{kHz}$ band and the proportion of benthic fleshy macroalgal cover $(\rho=0.63-0.7)$, an indicator of reef degradation. This study indicates the possibility of rapid, inexpensive and spatially integrative remote sensing of the ecological state of coral reefs. Such quantitative methods could be used to ecologically assess vast areas of reef habitat autonomously in near real-time and could be important for remote in situ detection and characterization of subtle but significant ecological changes brought about by climate change and other more localized anthropogenic impacts.
\end{abstract}

KEY WORDS: Underwater acoustics $\cdot$ Ecological survey $\cdot$ Monitoring $\cdot$ Coral reef $\cdot$ Marine ecology Hawaiian Islands

\section{INTRODUCTION}

Coral reefs are under threat from both climate change (Glynn 1996, Langdon et al. 2000, HoeghGuldberg 2011) and large-scale anthropogenic stressors that elicit complex ecosystem stress responses (Pastorok \& Bilyard 1985, Hughes 1994, Sebens 1994, Jackson et al. 2001, Pandolfi et al. 2003, 2005). Evaluation and monitoring of the ecological state of coral reefs is required for both scientific understanding and reef conservation initiatives. Classical coral reef ecological monitoring methods utilizing SCUBA diver

\footnotetext{
*Corresponding author: laurenava@gmail.com
}

surveys and substrate photography are both time and labor intensive. These techniques can introduce sampling error (due to the limited range of diver vision, optical sensors and diver endurance) and bias (due to the effect of the diver's presence on animal behavior). Furthermore, these surveys generally require a research vessel on station, and thus are not conducted frequently and cannot be conducted at night when benthic organisms are more active (Johnson et al. 1947, Freeman et al. 2014, Nedelec et al. 2015). The majority of faunal biomass on a coral reef may be small, cryptic and subterranean (Plaisance et al.

Outside the USA () The US Government 2016. Open Access under Creative Commons by Attribution Licence. Use, distribution and reproduction are unrestricted. Authors and original publication must be credited.

Publisher: Inter-Research · www.int-res.com 
2011). There is an urgent need for more quantitative, remote, less invasive and lower cost ecological data collection methods.

Passive acoustic monitoring of naturally occurring underwater sounds is a remote sensing method that may offer such ecosystem evaluation and monitoring capability. The underwater biophony, comprising sounds produced by biological processes (Pijanowski et al. 2011), contains the ecologically relevant information of interest. Some aspects of the biophony, such as marine mammal calls, are the subject of extensive study (Johnson et al. 2009, Richardson et al. 2013). However, the majority of acoustic energy in temperate and tropical shallow-water regions is created by a wide variety of other organisms including shrimp (Johnson et al. 1947, Au \& Banks 1998), lobsters (Moulton 1957, Patek et al. 2009), sea urchins (Cummings et al. 1964, Radford et al. 2008), hermit crabs (Freeman et al. 2014), as well as many species of soniferous fishes (Tavolga 1964, Rountree 2008). Ecological processes such as spawning (Tavolga 1964), feeding (Amorim et al. 2004), schooling and predator avoidance (Moulton 1960) create acoustic emissions that may contain information regarding the number and size of the organisms present, or the rate of resource consumption in that area. Indeed, some sounds play a role in the attraction of pelagic larvae to settlement sites (Simpson et al. 2004, 2005, Montgomery et al. 2006, Radford et al. 2007, Vermeij et al. 2010), suggesting that the correct interpretation of the information contained in these sounds confers selective advantage. Interest in using passive sounds as ecological metrics is growing (Cotter 2008). With the advancement of battery and solid-state memory technology, modern battery-powered underwater acoustic recorders can be deployed for a year or more and can take quality recordings at high sample rates and bit depths. Such sample rates not only permit the spectral investigation of higher frequency sounds but also facilitate detailed waveform analysis in the time domain (Au \& Banks 1998). While the sounds created by reef ecosystems contain a great deal of information, extracting useable ecological metrics from acoustic recordings remains a formidable challenge. Due to the complex nature of the acoustic environment in shallow water and the high degree of variability in sounds produced by organisms, careful interpretation and vetting of recordings with ecological data is necessary. Following work in terrestrial environments (Sueur et al. 2008, Depraetere et al. 2012), a number of recent studies (Kennedy et al. 2010, McWilliam \& Hawkins 2013, Lillis et al. 2014, Piercy et al. 2014, Nedelec et al. 2015) have explored rela- tionships between spectral and temporally filtered aspects of the underwater soundscape and ecological data using a variety of statistical techniques. Nighttime sound levels are observed to be generally higher in all studies, although attempts to quantify faunal activity through direct observation at night were problematic due to the need for divers to use illumination that (1) limited the observable area and (2) subsequently altered animal behavior (Nedelec et al. 2015). Nevertheless, it is generally accepted that nocturnal sound levels above several hundred Hertz are elevated due to invertebrate activity (Johnson et al. 1947, Freeman et al. 2014, Staaterman et al. 2013, 2014). While these levels have been linked in part to the activity of snapping shrimp (Johnson et al. 1947, Staaterman et al. 2013), evidence suggests that in some locations, a wide variety of organisms contribute to the general increase in level (Freeman et al. 2014, Radford et al. 2007, Kennedy et al. 2010). This paper aims to provide a holistic assessment of coral reef soundscapes in Hawaii, incorporating all of the biotic components without characterizing each individually.

\section{MATERIALS AND METHODS}

\section{Data collection and processing}

Data were collected in the Northwest Hawaiian Islands (NWHI) during NOAA Remote Areas Monitoring Program Cruise HA-12-04 on the R/V 'Hi'ialakai' during August 2012, and through shorebased operations throughout the main Hawaiian Islands (MHI) over the subsequent $8 \mathrm{wk}$ (Fig. 1 and Fig. S1 in Supplement 1 at www.int-res.com/articles/ suppl/m561p069_supp.pdf). Permits for conducting research within the $\mathrm{MHI}$, including some parks and protected areas, were provided by the Hawaii Department of Land and Natural Resources (DLNR Special Activity Permit 2012-83). Permits for conducting research in the NWHI were provided by the Papahanaumokuakea Marine National Monument (PMNM permit PMNM-2012-029). A limited number of sites were visited per island in the NWHI (Fig. S1A-D in Supplement 1) due to weather constraints and cruise scheduling. Acoustic data were not collected at some sites due to timing limitations and hardware failure, although at least 1 recording was obtained from each island in the NWHI and at least 3 from each island in the MHI (Fig. S1E-H). NWHI sites were selected based on prevailing weather conditions and proximity to the station site 


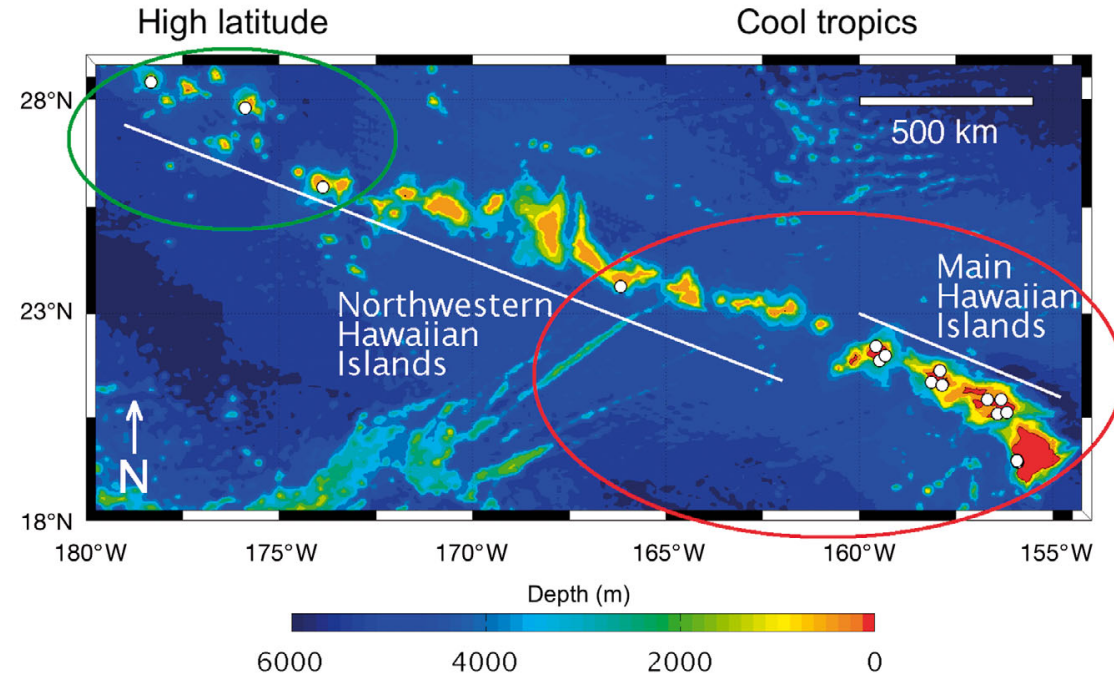

Fig. 1. Bathymetric chart of the study area in the Hawaiian Islands. The relative location of the Northwestern Hawaiian Islands (NWHI) and the Main Hawaiian Islands (MHI) is indicated by the white lines. The high latitude and cool tropics habitat regions (oceanographic habitats determined in Freeman et al. 2012) are indicated by the green and red ovals, respectively. Filled white circles indicate the locations of field sites where data were collected for this study. Land is denoted by the solid red color. The color bar indicates depth in meters. Smaller land-masses in the NWHI are too small to be visible at this scale

chosen by the captain of the R/V 'Hi'ialakai'. MHI site selection was based upon ease of accessibility from shore, weather conditions, and safety advice from knowledgeable locals. To mitigate for environmental noise, acoustic data were only collected in fair seas when Douglas Sea State remained between 0 and 4 .

\section{Time-lapse photography of benthic organisms}

Time-lapse photographic (TLP) data were collected using Canon D10 (or similar) underwater cameras programmed using the Canon Hack Development Kit open-source software package in a manner similar to that described in Freeman et al. (2012). Cameras were programmed to collect one image every $5 \mathrm{~min}$, using flash photography if light levels decreased below a software-determined threshold. Cameras were positioned above the substrate facing downward at a height of approximately $1 \mathrm{~m}$, or so that the field of view encompassed a benthic area of approximately $1 \mathrm{~m}^{2}$ (Fig. S2A in Supplement 1). To circumvent use of the autofocus light, which may have elicited a behavioral response from some organisms, each camera was manually focused in situ. Care was taken to ensure that cameras were deployed over substrate that was representative of the area. Four cameras were deployed at each site. TLP data that were limited by a hardware malfunction (fewer than 30 photos or out of focus) were discarded. In many cases, only 2 successful datasets were recorded per site. For sites with 3 or 4 series, only 2 were randomly selected for analysis to ensure consistency. Reef organisms were identified by eye, frame by frame, by trained observers. As the orientation of organisms, image quality, illumination and occluding material increased uncertainty when identifying organisms to the species level, counts of the photographed organisms were divided into the following, clearly identifiable groups: sea urchins (Echinoida and Cidaroida), crabs (Brachyura), hermit crabs (Paguroidea), brittle stars (Ophiuroidea), starfish (Asteroidea), sea cucumbers (Holothuroidea), fish (Osteichthyes), worms (Annelida and Polychaeta), eels (Muraenidae) and molluscs (Mollusca). These groups were selected based on the ability of the observers to identify organisms in the photographs, frequency of occurrence, and previous work that linked some of these groups to underwater sounds (Moulton 1957, 1960, Cummings et al. 1964, Tavolga 1964, Amorim et al. 2004, Radford et al. 2008, Patek et al. 2009, Freeman et al. 2014). An example of typical data from a crepuscular period recorded at Kahekili, Maui, is shown in Fig. 2. For each site, the average number of animals per frame was calculated for each group counted (Fig. S3A in Supplement 1). This average is the metric utilized in subsequent statistical analyses.

\section{Stationary point counts of fish}

Stationary point count (SPC) methods were based on NOAA Coral Reef Ecosystem Division (CRED) protocols for rapid ecosystem assessment (REA). All surveys were conducted at $10 \mathrm{~m}$ depth as fish assemblages at $10 \mathrm{~m}$ have been found to be equivalent to those at depths from 1 to $15 \mathrm{~m}$ (Friedlander et al. 2003). The observer remained in a stationary position $20 \mathrm{~m}$ away from TLP cameras and transect equipment. Fish longer than approximately $250 \mathrm{~mm}$ total length that entered a $20 \mathrm{~m}$ radius around the SPC diver were recorded during a timed 5 min count. Care was taken to avoid over-counting large transient or schooling 


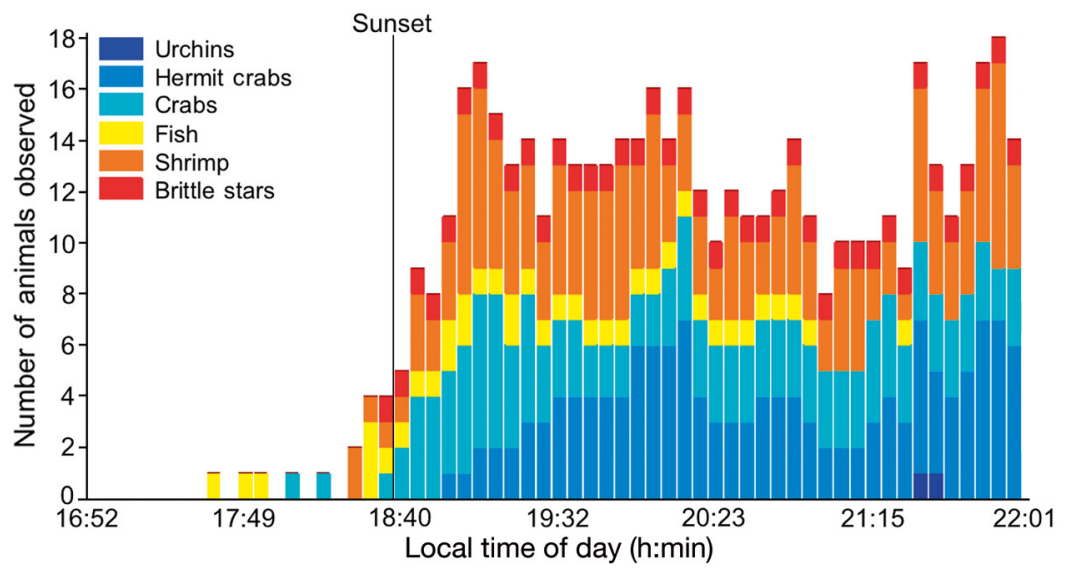

Fig. 2. Example time series of organism counts from time-lapse images taken at Kahekili, Maui. The horizontal axis indicates local time with sunset at 18:36 h, indicated by the vertical black line. Each color indicates a different organism type, stacked to indicate the total number of animals counted per photograph. Individual vertical bars represent one image in the time-lapse image series

fishes that left and subsequently re-entered the area. Observed fishes were identified to the following sub-groups: surgeonfishes (Acanthuridae), parrotfishes (Scaridae), drummers (Kyphosidae), squirrelfishes (Holocentrinae), wrasses (Labridae), jacks (Caranx ignobilis and C. melampygus), snappers (Lutjanidae), trumpetfishes (Aulostomus spp.), sharks (Carcharhinus galapagensis and Triaenodon obesus), pufferfishes (Tetraodontidae), groupers (Cephalopholis argus), scorpionfishes (Scorpaenidae), triggerfishes (Balistidae) and lizardfishes (Synodontidae) (Fig. S3B in Supplement 1). Per NOAA REA protocols, 2 replicate counts were conducted at each site, from which a mean was calculated for subsequent analyses. Group richness and Shannon diversity, an estimate of ecosystem entropy (Pielou 1966), were calculated from both the TLP and the SPC data sets.

\section{Benthic cover from photoquadrats}

Photoquadrat transects for the estimation of benthic cover were performed using REA methods utilized by NOAA CRED (Preskitt et al. 2004). Two $25 \mathrm{~m}$ transects were laid at a constant $10 \mathrm{~m}$ depth across the reef, passing directly under the hydrophone halfway along their length. Photographs were taken using a photoquadrat built to frame an area of $1 \mathrm{~m}^{2}$. Photographs were taken every meter, yielding 50 images per site. Ten randomly selected images were then processed using Photogrid photoquadrat image processing software. Due to permitting restrictions, verification of algal species was not conducted as no samples of algae or other substrate materials could be collected. Five hundred randomly distributed points were evaluated from the 10 images and an overall mean value for the following variables was established: percent cover of live coral, dead coral/rubble, crustose coralline algae (CCA), and fleshy/turf algae, and echinoderms, fish, sponges, reef cavities ('holes' in the reef) and sand/silt.

\section{Passive acoustic data}

A Loggerhead Instruments DSG Ocean single-channel, battery-powered acoustic recorder was deployed by divers at each field site for a minimum of $48 \mathrm{~h}$, during which directly observed data collection also took place. The device was secured to the sea floor using a sand anchor in $10 \mathrm{~m}$ depth, with the recorder positioned $2 \mathrm{~m}$ above the sea floor ( $8 \mathrm{~m}$ depth). The hydrophone employed by the recorder (High Tech, HTI-96-MIN) is largely omnidirectional in the radial direction over the frequency range of interest. The recorder was oriented vertically along a polypropylene line, held upright by a subsurface float (Fig. S2B in Supplement 1) in order to minimize the effects of the hydrophone's directionality and the air-filled battery compartment on the received field. It was assumed that most sound sources were positioned either on or close to the sea floor and that due to the shallow depth, direct and multipath arrivals from these sources arrived predominantly from directions other than the vertical. Hydrophones were deployed only in calm seas (Douglas sea state 0-4), distant from breaking waves to exclude physical environmental noise. Resultant spectrograms were inspected for boat noise and marine mammals. Boat noise was manually excluded when detected. Marine mammals, which create a unique spectral signature, were not detected in the recordings taken during this field campaign.

The recorder was configured to operate at a sample rate of 80000 samples s$^{-1}$, with 16 -bit resolution. Sys-

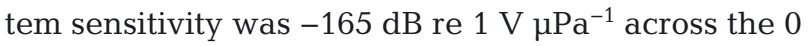
to $20 \mathrm{kHz}$ band. A duty cycle of $4 \mathrm{~min}$ of continuous recording every 5 min was employed to ensure battery power and memory capacity remained available over the entire $48 \mathrm{~h}$ deployment. Fig. 3 shows a typical $24 \mathrm{~h}$ period of recording in calm conditions during which no anthropogenic sound was evident. Sunrise 


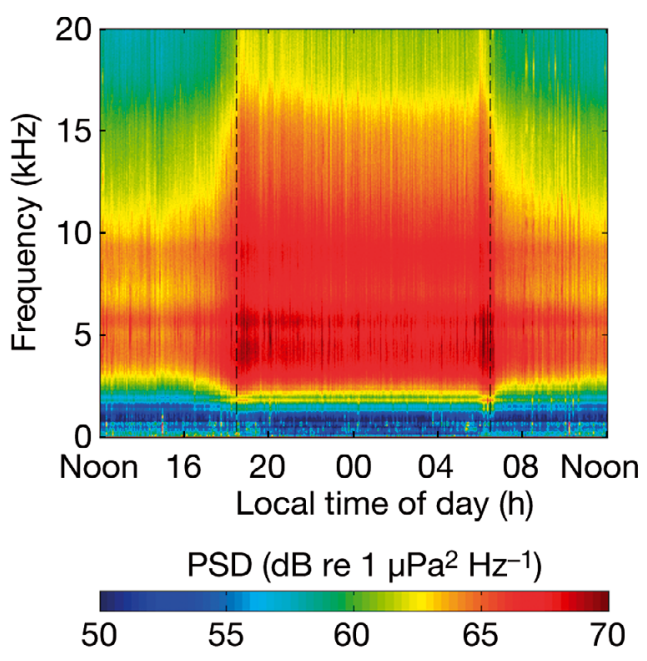

Fig. 3. Spectrogram showing typical reef sound patterns over a $24 \mathrm{~h}$ period from Ahukini, Kauai. The vertical dashed lines indicate (from left to right) sunset and sunrise times. The color scale indicates pressure spectral density (PSD) level

and sunset times were calculated using the GPSderived coordinates of each field site and a celestial calculator. Spectrograms of recordings from each field site were visually assessed in order to minimize or eliminate periods of recording during which anthropogenic noise, such as divers and boat activity, was evident. One-hour long segments from $2 \mathrm{~h}$ before and $1 \mathrm{~h}$ after sunrise and sunset (each consisting of twelve $4 \mathrm{~min}$ recordings, as sequential as possible) were used for the acoustic component of this study. Spectral estimates used for statistical analysis of the sound field were obtained using a 1024-point fast Fourier transform (FFT) with a $50 \%$ overlap, shaded with a Kaiser-Bessel window function $(\beta=2.5)$.

When viewed at sufficient temporal resolution, the underwater biological soundscape near reefs is often characterized by quiet periods broken by highly transient, impulse-like signals (Fig. 4). Two signal processing approaches were utilized to more accurately represent the frequency content of these individual biologically produced sounds and to minimize level bias introduced during the temporal integration necessary during FFTs. The short (1024-point, or $6.4 \mathrm{~ms}$ duration) FFT was used to reduce the probability of 2 transient arrivals being smeared together in a single spectral density estimate. Secondly, a temporal intensity filter was applied in which spectral estimates that contained no bin level greater than $102 \mathrm{~dB}$ re $1 \mathrm{\mu Pa}^{2} \mathrm{~Hz}^{-1}$ were excluded from analysis. These periods of relative quiet were less likely to contain biological sounds of interest and thus would skew means downward and toward lower frequency bins due to ever-present low-frequency wind and
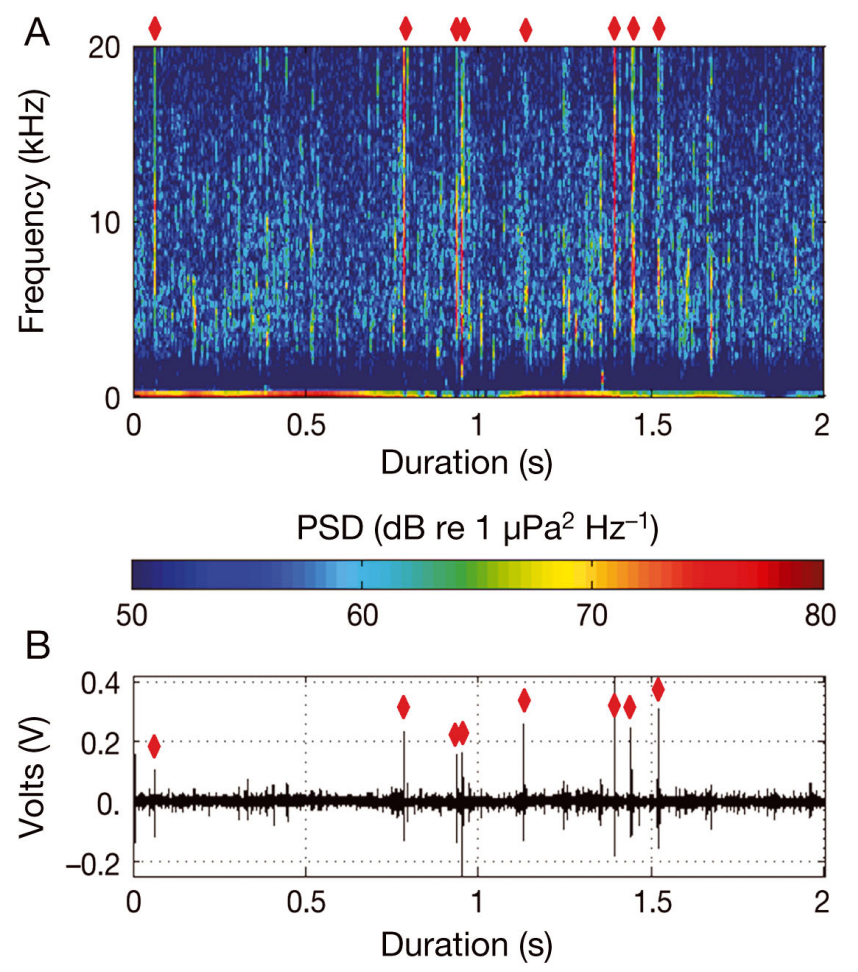

Fig. 4. Spectrogram (A) and associated raw time series (B) of a $2 \mathrm{~s}$ recording of ambient coral reef sound, sampled at Lisiansk/Neva Shoals using a 1024-point fast Fourier transform (FFT). An estimate every $6.4 \mathrm{~ms}$ reveals high levels of variation in spectral density over much of the band above $2 \mathrm{kHz}$. Such variation is smeared by longer FFTs as the longer 'snapshot' time combines the spectra of multiple impulse-like arrivals at the hydrophone. The solid red diamonds in both subfigures indicate individual impulse-like arrivals that were retained by the intensity filter. The unique spectrum of each is shown under the solid red diamonds in (A). PSD: pressure spectral density

wave noise. The resultant, concatenated spectral estimates are thus more likely to contain a higher temporal density of biologically produced acoustic information. The intensity threshold value was selected based on the maximum spectral density level produced by the snapping shrimp Synalpheus parneomeris $\left(124 \mathrm{~dB}\right.$ re $1 \mathrm{\mu Pa}^{2} \mathrm{~Hz}^{-1}$ at $1 \mathrm{~m}$ depth and $4 \mathrm{kHz}$ frequency; $\mathrm{Au} \&$ Banks 1998) over a circular area of $500 \mathrm{~m}^{2}$ around the hydrophone, the approximate area over which visual ecological data were obtained (a circular area of $25 \mathrm{~m}$ diameter, the length of the photo transects). While $S$. parneomeris is louder than most reef-dwelling organisms, it is one of very few invertebrates common in Hawaiian waters that has been acoustically characterized. The direct arrival of a 'snap' from $S$. parneomeris at the outer perimeter of the circular area would create a received level of approximately $102 \mathrm{~dB}$ re $1 \mu \mathrm{Pa}^{2} \mathrm{~Hz}^{-1}$ at the hydro- 
phone. While this conservative threshold level reduces the radius of sensitivity for quieter sounds, it serves as a benchmark based on source levels of a known soniferous invertebrate. As a result of filter implementation, analysis was performed on sequential, short periods of louder sounds and not the intervening quiet periods. To reduce the number of acoustic variables, spectral bins were divided into bands between 0.1 and $0.5,0.5$ and 1, 1 and 2, 2 and 7,7 and 13, and 13 and $20 \mathrm{kHz}$. The mean (over frequency) per-Hertz pressure spectral density was estimated in each band, before obtaining the average and standard deviation of the respective band values over each hour.

\section{Comparative statistical analysis}

Multivariate analyses were performed on both directly observed and acoustic data. These metrics included organism counts, total number of animals present in TLP counts, Shannon-Wiener diversity index and group richness from both SPC and TLP data. Acoustic variables for multivariate analysis were divided by time of day at which recordings were sampled (pre-sunrise, morning, afternoon and evening). All variables were normalized to a mean of 0 and a standard deviation of 1 . A principal component analysis (PCA) was then conducted with the normalized multivariate data to ascertain the inter-relatedness between various data metrics and sites. Zero-inflated metrics were excluded from the PCA (Zuur et al. 2010). The PCA results presented here include a limited number of variables found to be most significant in earlier iterations. Pearson's correlations between all variables, including acoustic variables recorded at different times of day, were calculated over all field sites. Metrics for which Pearson's $\rho$ values were greater than 0.6 with $p<0.001$ (Bonferroni correction) were considered to be sufficiently correlated and were subject to further analysis. Correlations of particular interest were those that appeared to form a distinct pattern across several metrics (i.e. a high degree of correlation between the presence of an organism and multiple acoustic frequency bands) (Table S2 in Supplement 2 at www.int-res.com/articles/ suppl/m561p069_supp.xlsx).

\section{RESULTS}

Field sites ranged from intact coral reefs to rubblestrewn sand and algal mats. Fig. 5 provides an indication of the diversity of local environments sampled in this study. Similar data from TLP and SPC data collections are provided in Fig. S3 in Supplement 1. Stronger associations between acoustic and directly observed variables provide the basis for creating ecological proxies based on acoustic recordings. Consequently, observed relationships between the soundscape and visually obtained data are reported here, rather than the absence of correlative links. PCA outputs (Fig. 6) and Pearson's correlations (Table 1) reveal associations between acoustic variables and observations from TLP, SPC and photoquadrat data that were consistent across the entire Hawaiian archipelago, and within the 2 oceanographic habitats considered (Freeman et al. 2012).

TLP-derived benthic invertebrate counts (hermit crabs and urchins) were correlated with mean

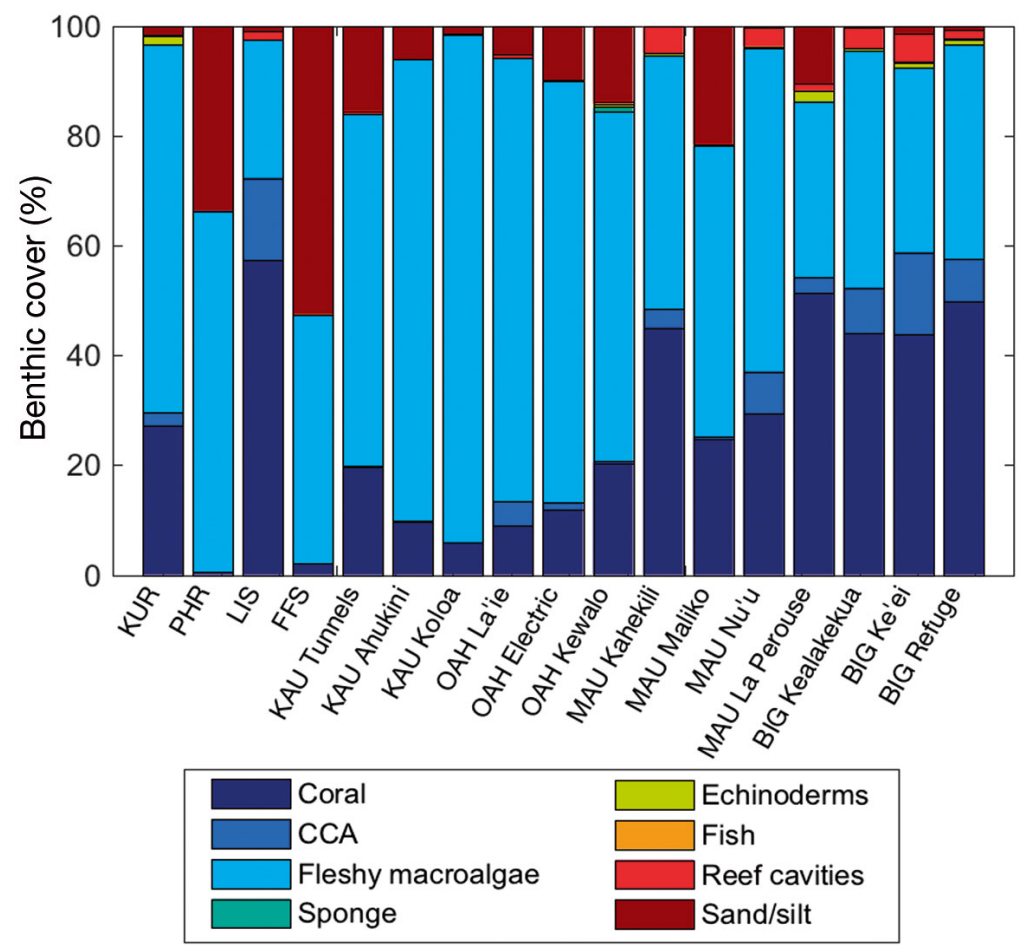

Fig. 5. Benthic composition estimates of individual sites in the Hawaiian Islands (see Fig. S1, Table S1 in Supplement 1 at www.int-res.com/articles/ suppl/m561p069_supp.pdf). The proportions shown here were obtained from photoquadrat image analysis for each individual site (listed on the horizontal axis). The relative proportion of each bottom type is shown by the height of the color bar, stacked to show the full composition of each site. The results shown here are average percent benthic cover per site. Sites are ranked in order of decreasing latitude. KUR: Kure Atoll, PHR: Pearl and Hermes reed, LIS: Lisianski Island, FFS: French Frigate Shoals, KAU: Kauai, OAH: Oahu, MAU: Maui, BIG: Big Island 


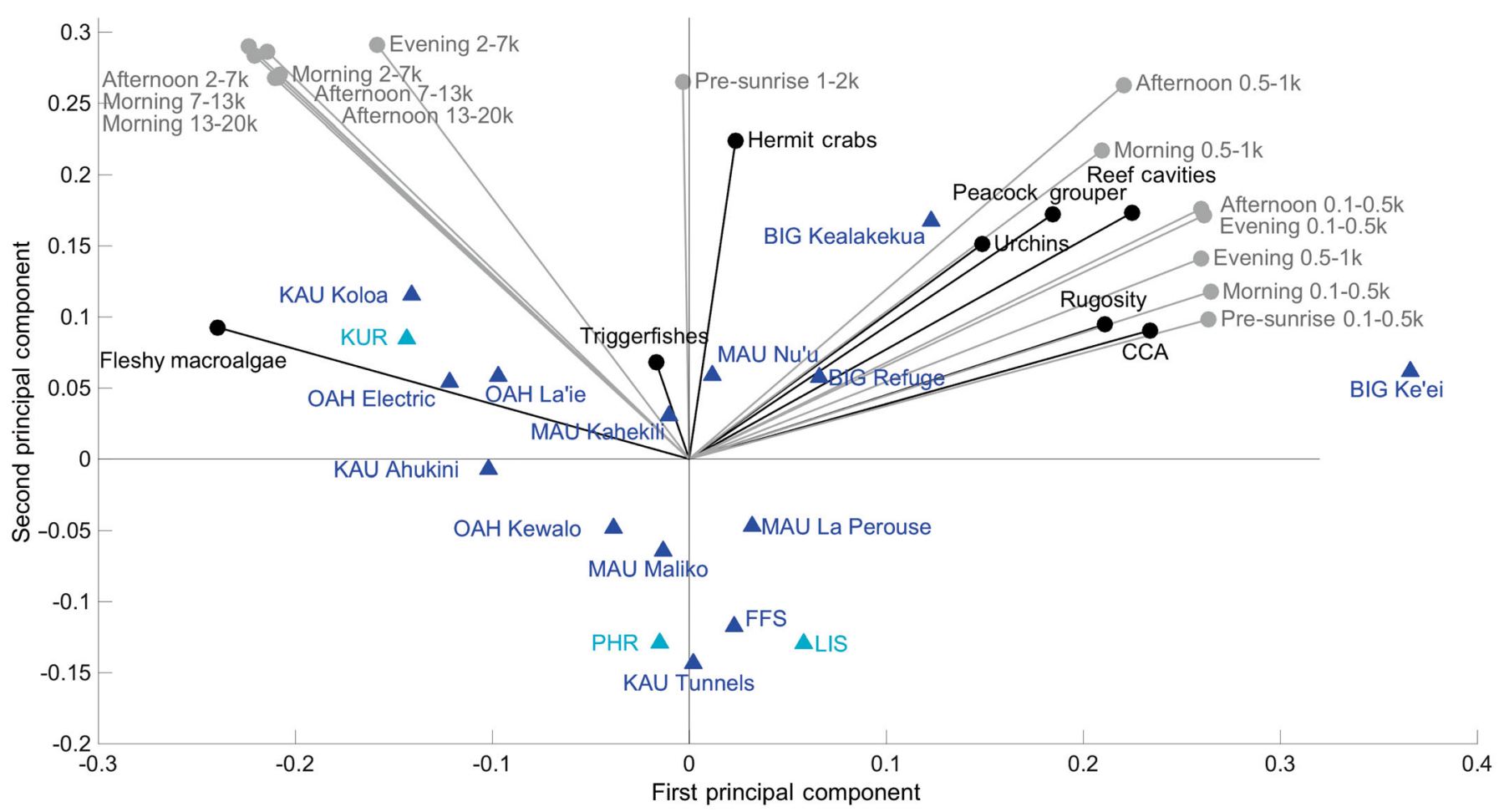

Fig. 6. Principal component analysis of passive acoustic, remote camera and directly observed ecological variables for 17 coral reef sites in the Hawaiian Islands (see Fig. 5 for abbreviations and Fig. S1, Table S1 in Supplement 1 for locations). The first 2 components plotted here explain $68 \%$ of the total variance. Black lines and filled circles indicate directly observed, nonacoustic variables. Grey lines and filled circles indicate mean acoustic pressure spectral density levels during the periods and within the bands indicated (k: kHz). Dark blue and cyan triangles indicate the position of field sites within the 'cool tropics' and 'high latitudes' oceanographic regimes, respectively (Freeman et al. 2012). A general trend from 07:00 to 14:00 h is evident in the sites ranging from more algae-dominated to more coral-dominated, which is also reflected in the acoustic metrics with low-frequency sounds characterizing reefs with positive ecological indicators, and high-frequency sounds characterizing reefs with negative ecological indicators

sound levels in the 1 to $2 \mathrm{kHz}$ and $500 \mathrm{~Hz}$ to $1 \mathrm{kHz}$ bands before dawn and in the morning, respectively (Fig. 7A,B). Sound levels in these same frequency bands were also correlated with SPC counts of reefbased predators of benthic fauna, such as triggerfish (Melichthys and Rhinecanthus sp., Fig. 7C) and peacock grouper (Cephalopholis argus, Fig. 7D).

Correlations were also observed between photoquadrat-derived benthic cover estimates and specific components of the acoustic spectrum. Rugosity (smallscale bottom complexity, obtained through direct measurement) and reef cavities (obtained through photoquadrat estimates) are both indicators of centimeter-scale surface roughness. These 2 data sets were obtained through unique methods. Both were correlated with low-frequency biological sounds in the 100 to $1000 \mathrm{~Hz}$ bands (Fig. 8). Rugosity (Fig. 8A) was positively correlated with mean sound levels in the 100 to $500 \mathrm{~Hz}$ and $500 \mathrm{~Hz}$ to $1 \mathrm{kHz}$ bands recorded in the afternoon and evening, respectively. Reef cavities (Fig. 8B) were positively correlated with mean sound levels in the 100 to $500 \mathrm{~Hz}$ band during all periods of recording. The proportion of hard reef substrate covered by CCA was correlated with mean sound levels in the 100 to $500 \mathrm{~Hz}$ and $500 \mathrm{~Hz}$ to $1 \mathrm{kHz}$ bands, recorded during the day and after sunset, respectively (Fig. 9). Most correlations between directly observed and acoustic data pertained to sound below $2 \mathrm{kHz}$. However, photoquadrat-derived estimates of the proportion of substrate covered by fleshy macroalgae were correlated with almost all daytime acoustic metrics in the 2 to $20 \mathrm{kHz}$ bands (Fig. 10).

\section{DISCUSSION}

The inclusion of a wide range of field sites along the Hawaiian Island chain provides broad-reaching inferences regarding associations of specific bandwidths with indicators of coral reef ecological state. Multivariate analysis teases apart local variation 
Table 1. Correlations between ecological variables and mean acoustic pressure spectral density of coral reef sites in the Hawaiian Islands. Pairs of ecological and acoustic variables for which Pearson's correlation coefficient values were equal to or greater than 0.6 are shown (the complete data set is available in Table S2 in Supplement 2 at www.int-res.com/articles/suppl/m561p069_supp.xlsx). Acoustic recording periods are described by the time of day. Also shown are the acoustic frequency bands from which pressure spectral densities were obtained, as well as Pearson's correlation coefficient $\rho$. CCA: crustose coralline algae

\begin{tabular}{|c|c|c|c|}
\hline Ecological variable & Time of day & $\begin{array}{l}\text { Acoustic frequency } \\
\text { band }(\mathrm{kHz})\end{array}$ & $\begin{array}{c}\text { Pearson's } \\
\text { coefficient, } \rho\end{array}$ \\
\hline Urchin sp. (mean no.) & Morning & $0.5-1$ & 0.76 \\
\hline Hermit crab sp. (mean no.) & $\begin{array}{l}\text { Pre-sunrise } \\
\text { Afternoon }\end{array}$ & $\begin{array}{l}1-2 \\
1-2\end{array}$ & $\begin{array}{l}0.61 \\
0.61\end{array}$ \\
\hline Triggerfish sp. (mean no.) & Evening & $1-2$ & 0.65 \\
\hline Peacock grouper (mean no.) & $\begin{array}{l}\text { Morning } \\
\text { Afternoon }\end{array}$ & $\begin{array}{l}0.5-1 \\
0.5-1\end{array}$ & $\begin{array}{c}0.8 \\
0.61\end{array}$ \\
\hline Rugosity & $\begin{array}{l}\text { Afternoon } \\
\text { Evening }\end{array}$ & $\begin{array}{l}0.1-0.5 \\
0.1-0.5\end{array}$ & $\begin{array}{c}0.6 \\
0.62\end{array}$ \\
\hline Reef cavities ( $\%$ cover) & $\begin{array}{l}\text { Pre-sunrise } \\
\text { Morning } \\
\text { Afternoon } \\
\text { Afternoon } \\
\text { Evening } \\
\text { Evening }\end{array}$ & $\begin{array}{c}0.1-0.5 \\
0.1-0.5 \\
0.1-0.5 \\
0.5-1 \\
0.1-0.5 \\
0.5-1\end{array}$ & $\begin{array}{l}0.6 \\
0.61 \\
0.67 \\
0.73 \\
0.66 \\
0.63\end{array}$ \\
\hline CCA (\% cover) & $\begin{array}{l}\text { Morning } \\
\text { Afternoon } \\
\text { Afternoon } \\
\text { Evening }\end{array}$ & $\begin{array}{c}0.1-0.5 \\
0.1-0.5 \\
0.5-1 \\
0.1-0.5\end{array}$ & $\begin{array}{c}0.61 \\
0.61 \\
0.62 \\
0.6\end{array}$ \\
\hline Fleshy algae ( $\%$ cover) & $\begin{array}{l}\text { Morning } \\
\text { Morning } \\
\text { Morning } \\
\text { Afternoon } \\
\text { Afternoon } \\
\text { Afternoon }\end{array}$ & $\begin{array}{c}2-7 \\
7-13 \\
13-20 \\
2-7 \\
7-13 \\
13-20\end{array}$ & $\begin{array}{c}0.63 \\
0.7 \\
0.68 \\
0.67 \\
0.68 \\
0.67\end{array}$ \\
\hline
\end{tabular}

(Radford et al. 2010) from ecosystem-wide trends. Correlations between ecosystem indicators and components of the soundscape cannot provide definitive explanations of cause and effect. Apart from unknowns regarding how, why and what fauna create these sounds, the quantification of attenuation and scattering from highly heterogeneous substrates and complex bathymetry is also necessary to fully understand the connection between biological soundscapes and the organisms that create them.

In general, greater sound levels in the band below $1 \mathrm{kHz}$ were associated with sites characterized by positive ecological metrics such as greater CCA cover, bathymetric complexity (associated with branching coral structures) and numbers of benthic organisms. Sites that were characterized by high levels of fleshy macroalgae, an indicator of a coral reef in decline or one in which an ecological shift to a more degraded state had occurred, were simultaneously characterized by relatively greater sound levels at higher frequencies (2 to $20 \mathrm{kHz}$ ). The PCA results show frequency-gradated structure from left (high-frequency acoustic metrics, more degraded reef sites) to right (low-frequency acoustic metrics, more intact reef sites), nearly along the first principal component, which explained $43 \%$ of the variance. Generally, the least degraded reefs, including several in marine protected areas, aligned towards the $2 o^{\prime}$ clock position, while the more degraded reefs aligned towards the 7 o'clock position (Fig. 6).

The mapping of reef state along the first principal component is more pronounced when oceanographic habitat is considered (Figs. 1 \& 6) (i.e. only the cool tropics reefs or only the high latitude reefs from Freeman et al. 2012). Measurements, particularly of algae-related metrics, from the high-latitude reefs may be confounded by differing oceanographic conditions in those areas (cooler temperatures, higher frequency of winter storms, etc.) that produce more favorable environments for algal growth. Consequently, reefs in this region may be associated with increased levels of higher frequency sound even if they are relatively undisturbed (i.e. Kure Atoll, Fig. 10). This acoustic delineation may be important for passive acoustic monitoring in the study of climate change impacts, which are projected to be less severe in the high latitude reefs than the cool tropics reefs (Freeman 2015).

Sound levels below $1 \mathrm{kHz}$ appear to be associated with indicators of a healthy coral reef ecosystem state. Studies in other regions (Piercy et al. 2014, Kaplan et al. 2015) have also observed a positive correlation between spectral levels in this band and indicators of ecosystem function. It is intuitive to surmise that greater numbers of acoustically active organisms would create louder biological soundscapes. However, the correlation between sound, rugosity, benthic porosity and CCA cannot be explained directly. Bottom roughness and CCA do not create sound by themselves, thus an additional layer of interaction between these environmental aspects and soniferous organisms must exist. The acoustic metrics derived from recordings at sites that are more disparate ecologically 

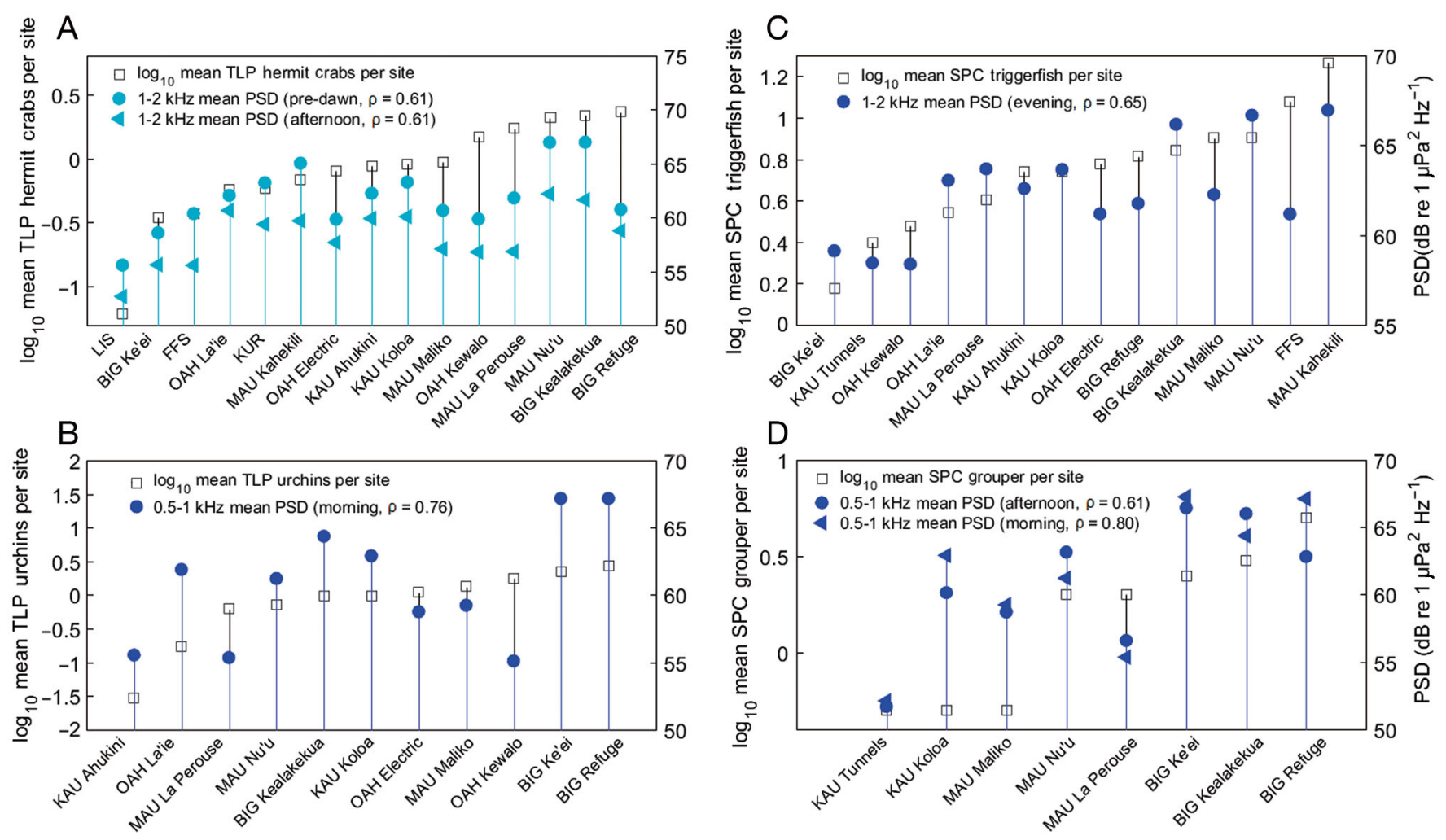

Fig. 7. Correlation between benthic organisms, their predators and low-frequency acoustic pressure spectral density (PSD) at coral reef sites in the Hawaiian Islands (see Fig. 5 for abbreviations and Fig. S1, Table S1 in Supplement 1 for locations). Timelapse photography (TLP)-derived (A) hermit crab counts, (B) urchins, stationary point count (SPC)-derived (C) triggerfishes and (D) peacock groupers shown against mean PSD levels of correlated acoustic bands and times of day. The left axes indicate the logarithm of organism counts, while the right axes indicate mean PSD levels in $\mathrm{dB}$ re $1 \mu \mathrm{Pa}^{2} \mathrm{~Hz}^{-1}$. The horizontal axis indicates sites from which both data sets were available

(i.e. Ke'ei on the Big Island, Fig. 8) follow the correlative trend of greater sound levels at higher frequencies in more degraded ecosystems, and greater sound levels at low frequencies in more intact ecosystems, suggesting that the relationships between certain aspects of the soundscape, benthic algae and topography remain intact across very different reef ecosystem states.

The presence of some benthic organisms and their predators (Figs. 6 \& 7) was associated with sound levels in low-frequency bands (generally $100 \mathrm{~Hz}$ to $1 \mathrm{kHz}$ ). The low-frequency sounds produced by invertebrates have been associated with feeding and motion (Radford et al. 2008, Freeman et al. 2015). Low-frequency sounds produced by predatory fishes (triggerfishes, groupers) in the same band have been associated with territorial and conspecific interactions (Tricas \& Boyle 2014). Such communication between these predators shows that they are sensitive to sounds at frequencies less than $1 \mathrm{kHz}$. It is thus possible, although unproven, that adult fishes use invertebrate sound to locate areas with greater numbers of potential prey. While the use of ambient underwater sound as a cue for larval fishes has been well studied (Simpson et al. 2004, 2005, Montgomery et al. 2006, Radford et al. 2007), the use of sound to guide adult fish to a food source has not been rigorously studied. The results shown here do not preclude such behavior.

The similar correlations between low-frequency $(100 \mathrm{~Hz}$ to $1 \mathrm{kHz})$ sound levels with rugosity and the occurrence of reef cavities (Figs. 6 \& 8) strengthen the link between these sounds and bathymetric complexity at centimeter scales. These 2 variables were sampled through independent means, each with a unique susceptibility to bias. Rugosity measurements, collected by divers using a fine chain and measuring tape, can be prone to bias through underestimation of bottom complexity as any tension on the measuring chain reduces estimates of surface roughness. Photoquadrat-derived estimates of reef cavity cover are subject to completely different bias mechanisms, such as the influence of incident light in illuminating or shading parts of the benthos, remov- 

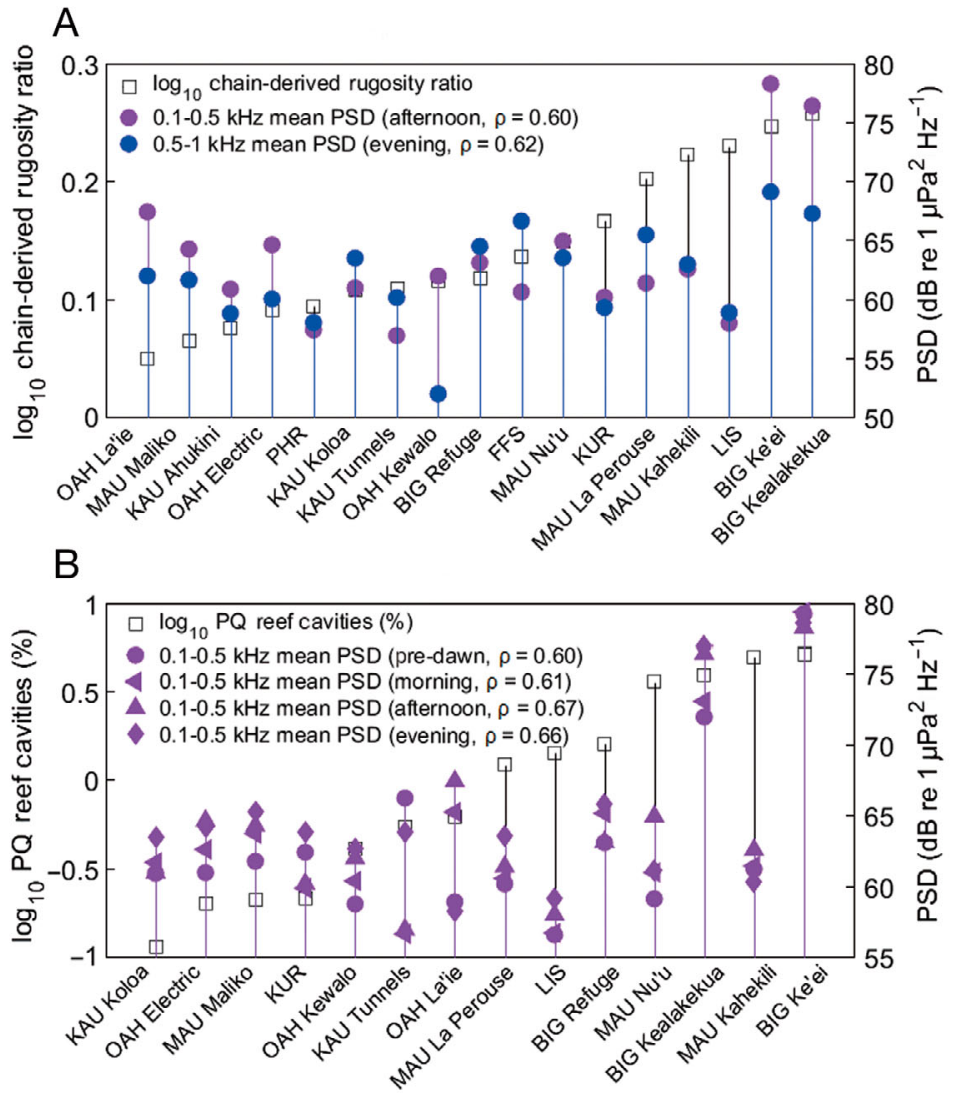

Fig. 8. Correlation between reef structure and low frequency acoustic pressure spectral density (PSD) at coral reef sites in the Hawaiian Islands (see Fig. 5 for abbreviations and Fig. S1, Table S1 in Supplement 1 for locations). (A) Rugosity ratio estimates and (B) photoquadrat (PQ)-derived reef cavities against mean PSD levels of correlated acoustic bands and times of day. The left axes indicate the logarithm of rugosity ratio in (A) and the logarithmic proportion of photoquadrat images identified as deep holes in the reef in (B). The right axes indicate mean PSD levels in $\mathrm{dB}$ re $1 \mathrm{\mu Pa}^{2} \mathrm{~Hz}^{-1}$. The horizontal axis indicates sites from which both data sets were available

ing or producing the appearance of deep holes in the reef surface, respectively. The mechanisms behind these correlations are likely driven by the increased roughness providing more preferable habitat for cryptic organisms known to create sounds in these acoustic bands. Greater benthic complexity offers increased surface area for sessile food sources, and more opportunity to avoid predation through remaining hidden in the often complex labyrinth of subsurface voids and overhanging environments typically found on a healthy coral reef.

In addition to rugosity and surface porosity, sound levels in the $100 \mathrm{~Hz}$ to $1 \mathrm{kHz}$ bands during all times of day was correlated with CCA. Rugosity and CCA are associated with a more intact coral reef ecosystem. CCA contributes significantly to reef calcification and formation, binding coral and rubble together and, as a result, increasing resistance to storms (Fabricius \& De'ath 2001). CCA increases the complexity of structures within the reef and the volume of available habitat for subsurface reef creatures (Birrell et al. 2008), thus CCA is also positively related to rugosity and surface porosity. Surfaces covered in CCA are preferred settlement sites for coral planulae (Tebben et al. 2015). The presence of CCA is also an indicator of active herbivory, as CCA must be cleaned of fleshy algae that continually colonize its surface (Steneck 1983). The relative abundance of $\mathrm{CCA}$, and its correlation with low-frequency biological sound, further indicates that sound levels in the bands below $1 \mathrm{kHz}$ are positively associated with many aspects of a healthy coral reef state.

It should be noted that while many marine organisms are known to produce sound below $1 \mathrm{kHz}$, physical processes such as sea state and breaking waves, and anthropogenic sources such as vessel traffic also ensonify this band. Care was taken both in the field, with site selection and deployment timing, as well as during processing, to minimize and remove noise from boat traffic and breaking waves. No marine mammals were observed or recorded during deployments.

The dominance of fleshy macroalgae over reef-building corals is an indicator of a degraded ecosystem state (Pandolfi et al. 2005). The results show that the proportion of fleshy algae covering hard substrate correlates with most acoustic metrics between 2 and $20 \mathrm{kHz}$, but only from recordings taken during the day (Fig. 10). The uniformity of correlation between algal cover and acoustic variables from these acoustic bands was further underscored by the lack of correlation between these bands and any other directly observed metrics. The causal connection between high-frequency sound levels and macroalgae cannot be determined from the information published here. However, a causative link between high-frequency components of the soundscape and algal cover may involve the association between algae and acoustically active fauna that may graze on or reside in habitat created by fleshy algae. Sounds created by snapping shrimp dominate the highfrequency component of the soundscape in many coastal areas (Au \& Banks 1998). It is possible that areas covered by higher proportions of fleshy algae are preferred habitats for some species of snapping 


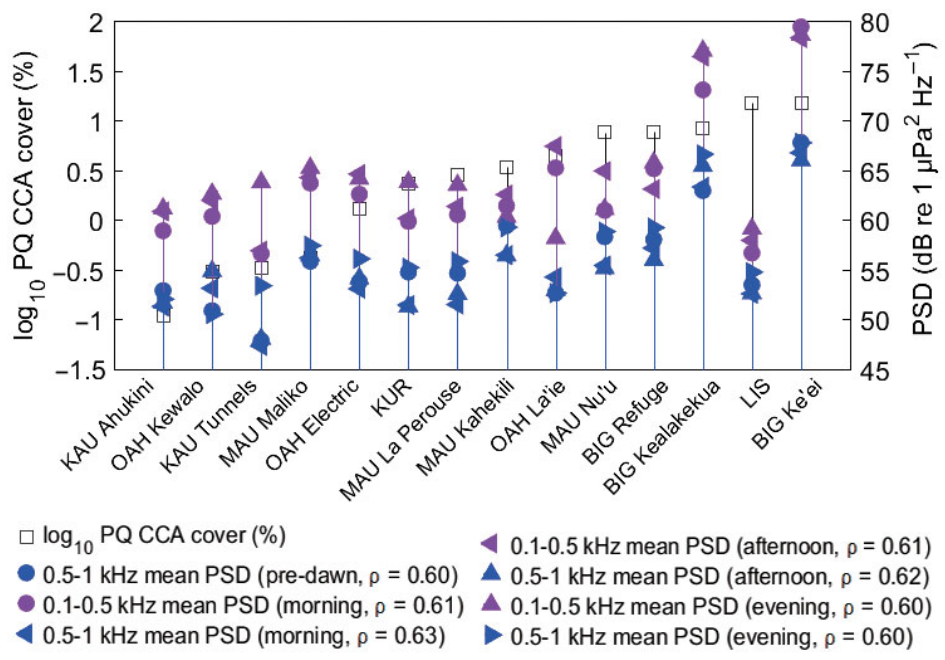

Fig. 9. Correlation between crustose coralline algae (CCA) and lowfrequency acoustic pressure spectral density (PSD) at coral reef sites in the Hawaiian Islands (see Fig. 5 for abbreviations and Fig. S1, Table $\mathrm{S} 1$ in Supplement 1 for locations). Photoquadrat (PQ)-derived CCA cover against mean PSD levels of correlated acoustic bands and times of day. The left axis indicates the log proportion of photoquadrat images covered by CCA, while the right indicates mean PSD levels in $\mathrm{dB}$ re $1 \mu \mathrm{Pa}^{2} \mathrm{~Hz}^{-1}$. The horizontal axis indicates sites from which both data sets were available

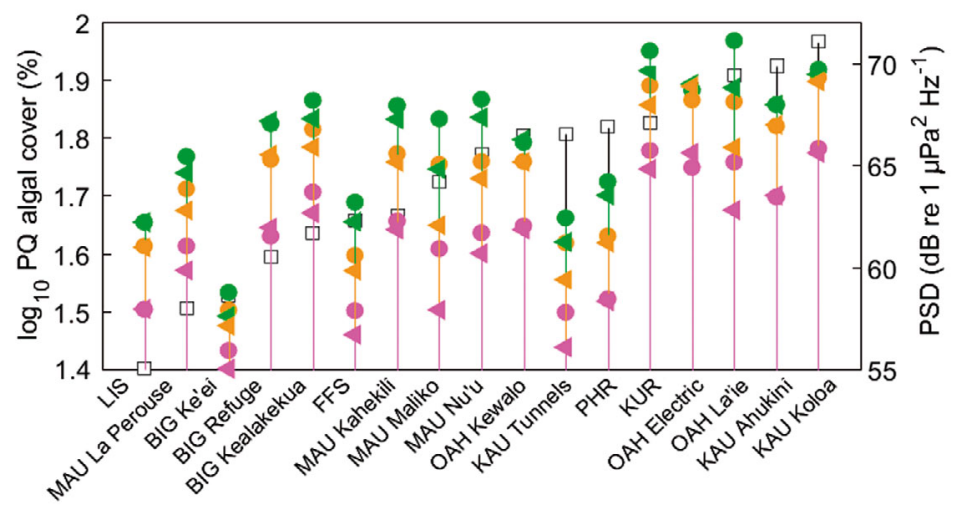

$\square \log _{10} P Q$ algal cover (\%)

- 2-7 kHz mean PSD (morning, $\rho=0.63$ ) $42-7 \mathrm{kHz}$ mean PSD (afternoon, $\rho=0.67$ )

- 7-13 kHz mean PSD (morning, $\rho=0.70)<7-13 \mathrm{kHz}$ mean PSD (afternoon, $\rho=0.67$ )

- 13-20 kHz mean PSD (morning, $\rho=0.68$ ) $\varangle 13-20 \mathrm{kHz}$ mean PSD (afternoon, $\rho=0.67$ )

Fig. 10. Correlation between fleshy macroalgae cover and highfrequency acoustic pressure spectral density (PSD) at coral reef sites in the Hawaiian Islands (see Fig. 5 for abbreviations and Fig. S1, Table $\mathrm{S} 1$ in Supplement 1 for locations). Photoquadrat (PQ)-derived fleshy macroalgae cover against mean PSD levels of correlating acoustic bands and times of day. The left axis indicates the log proportion of photoquadrat images covered by fleshy macroalgae, while the right indicates mean pressure PSD levels in $\mathrm{dB}$ re $1 \mathrm{\mu Pa}^{2} \mathrm{~Hz}^{-1}$. The horizon-

tal axis indicates sites from which both datasets were available

shrimp, and that their presence contributes to an indirect association between algae and high-frequency sounds. Nondestructively determining whether there is any such relationship may be challenging as snapping shrimp are usually subterranean creatures and are rarely observed above the substrate. Directional acoustic receivers may be employed to determine the location of snaps in an area (Ferguson \& Cleary 2001, Chitre et al. 2012, Kaplan et al. 2015), producing estimates of snapping shrimp distribution in a localized area. Regardless of the process that connects high-frequency sound and the proportion of algal cover, the correlative findings shown here introduce the possibility of an acoustic indicator of algal dominance, and in some situations, of reef degradation. Controlled studies that exclude soniferous fauna are required to conclusively evaluate the mechanisms behind the association between algae and high-frequency components of the soundscape.

The passive acoustic evaluation techniques discussed here are not limited to use in shallow-water coral reef environments. Any underwater environment in which organisms ensonify the medium may be subject to passive ecological monitoring. These techniques may be particularly useful in environments that are difficult to access, such as benthic ecosystems under ice or those in deep water. Modern battery performance now enables multi-year deployments of persistently recording remote acoustic sensors. Recorders in shallow water equipped with satellite telemetry could relay data products, processed onboard, in real time. Such sensors are routinely mounted on autonomous vehicles, enabling the acoustic survey of large areas in relatively short time frames. However, different types of ecosystems may produce unique ecologicalacoustic associations that would require independent validation.

The single hydrophone recorders used in this study, and most other underwater soundscape studies, are largely omnidirectional and do not permit sound source localization or spatial filtering of undesirable noise. These limitations are significant shortcomings that can be overcome using directional receivers such as hydrophone array systems and associated array processing algorithms. In a shallow-water coral reef environment, benthic sound sources are sandwiched between the pressure-release surface and a hard bottom consisting of limestone bedrock. Consequently, the environment is a highly reverberant one, further complicated by scattering from the intricate wavelength-scale geo- 
metries of reef-building corals. While this study observed correlations between recordings made by a single hydrophone and high-level ecological metrics, more detailed analysis of underwater soundscapes will most likely require directional receivers in order to filter out unwanted noise from other parts of the reef and from non-biological sources. Furthermore, in addition to array gain, modern array processing techniques such as adaptive and compressive beamforming (Cox et al. 1987, Edelmann \& Gaumond 2011) may be applied to further enhance the spatial resolution of directional recorders in this setting.

\section{CONCLUSIONS}

This study reports on correlations between aspects of the underwater biological soundscape and concurrent, visually observed ecological metrics over the Hawaiian Islands archipelago. The associations remain consistent across substantially varying local underwater environments, implying that they represent the more fundamental ecological processes that characterize different types of underwater ecosystems in the archipelago. The relationships between acoustic metrics and coral reef ecological metrics are most pronounced when controlling for oceanographic habitat, suggesting that comparative acoustic metrics function best when sampling is conducted across an area homogeneous in oceanographic regime. Trends in coral reef state were identified that may be ascertained solely from acoustic metrics as a means of large-scale, passive remote monitoring. A frequency-dependent gradient was observed, where less impacted sites are typified by a low-frequency dominated soundscape, and greater high-frequency ambient sound levels typified sites where algae dominated the benthic structure. Positive correlations between low-frequency $(<1 \mathrm{kHz})$ components of the soundscape and benthic invertebrates, predators of benthic invertebrates, centimeter-scale bathymetric complexity and CCA suggest that sound levels in this band may be positively associated with habitat availability and the density of benthic fauna. Positive correlations between components of the soundscape in the 2 to $20 \mathrm{kHz}$ band and algal cover infer a connection between fleshy algae, an indicator of reef degradation, and higher frequency sound. The correlations reported here between directly observed ecosystem metrics and aspects of the biological soundscape encourage further, large-scale work toward the passive acoustic monitoring of reef environments. These results present the possibility of a more integrative, deterministic and non-destructive means of evaluating ecosystem state that is unconstrained by the bias and error associated with traditional diver-based ecosystem monitoring techniques. The required technology exists in an inexpensive, field-proven form today, and our knowledge of underwater acoustic propagation and signal processing benefits from vast and exhaustive research efforts, albeit for military purposes, over the last 70 years. Such knowledge and mature technology, when bought to bear on complex problems such as ecological monitoring, could dramatically improve accuracy and spatiotemporal resolution when estimating the actual in situ impacts of overfishing, pollution, shipping, tourism and climate change.

Acknowledgements. The authors are grateful for the permitting and fieldwork assistance provided by M. Lammers of the Oceanwide Science Institute, Honolulu, HI; P. FisherPool and the Coral Reef Ecosystem Division, NOAA Hawaii; the captain and crew of the RV 'Hi'ialakai' and the science team from cruise HA-12-04, in particular, Chief Scientist S. Godwin; the Papahanaumokuakea Pacific Marine National Monument, Hawaii; and S. Garcia, R. Grenzeback, S. Stevenson and S. Davis. A. Miller, R. Norris, G. D'Spain, M. Buckingham and G. Deane of Scripps Institution of Oceanography provided advisory support and technical expertise. F. Rohwer of San Diego State University provided the hydrophone system. T. Lilley (Kauai), S. Mycklebust and L. Mycklebust (Hawaii), and E. Kelly and L. Lewis (Maui) provided local knowledge. P. Franck provided assistance with data processing. G. Orris, M. Kappus and S. Ackleson of the Naval Research Laboratory, Washington, DC, provided logistics support for data processing and writing. This research was conducted in part while L.A.F. held an NRC Research Associateship at the US Naval Research Laboratory. Three anonymous reviewers provided valuable editorial suggestions that greatly improved the quality of the manuscript.

\section{LITERATURE CITED}

Amorim MCP, Stratoudakis Y, Hawkins AD (2004) Sound production during competitive feeding in the grey gurnard. J Fish Biol 65:182-194

Au WW, Banks K (1998) The acoustics of the snapping shrimp Synalpheus parneomeris in Kaneohe Bay. J Acoust Soc Am 103:41-47

Birrell CL, McCook LJ, Willis BL, Diaz-Pulido GA (2008) Effects of benthic algae on the replenishment of corals and the implication for the resilience of coral reefs. Oceanogr Mar Biol Ann Rev 46:25-63

Chitre M, Kuselan S, Pallayil V (2012) Ambient noise imaging in warm shallow waters; robust statistical algorithms and range estimation. J Acoust Soc Am 132:838-847

Cotter JR (2008) The 'soundscape' of the sea, underwater navigation, and why we should be listening more. In: Payne A, Cotter J, Potter T (eds) Advances in fisheries science: 50 years on from Beverton and Holt. Blackwell Publishing, Oxford, p 451-471 
Cox H, Zeskind RM, Owen MM (1987) Robust adaptive beamforming. IEEE Trans Acoust Speech Signal Process 35:1365-1376

Cummings WC, Brahy BD, Herrnkind WF (1964) The occurrence of underwater sounds of biological origin off the west coast of Bimini, Bahamas. In: Tavolga WN (ed) Marine bio-acoustics. Pergamon, New York, NY, p 27-43

Depraetere M, Pavoine S, Jiguet F, Gasc A, Duvail S, Sueur J (2012) Monitoring animal diversity using acoustic indices: implementation in a temperate woodland. Ecol Indic 13:46-54

Edelmann GF, Gaumond CF (2011) Beamforming using compressive sensing. J Acoust Soc Am 130:EL232-EL237

* Fabricius K, De'ath G (2001) Environmental factors associated with the spatial distribution of crustose corraline algae on the Great Barrier Reef. Coral Reefs 19:303-309

Ferguson BG, Cleary JL (2001) In situ source level and source position estimates of biological transient signals produced by snapping shrimp in an underwater environment. J Acoust Soc Am 109:3031-3037

Freeman LA, Miller AJ, Norris RD, Smith JC (2012) Classification of remote Pacific coral reefs by physical environment. J Geophys Res Oceans 117:C02007

*Freeman SE, Rohwer FL, D'Spain GL, Friedlander AM, Gregg AK, Sandin SA, Buckingham MJ (2014) The origins of ambient biological sound from coral reef ecosystems in the Line Islands archipelago. J Acoust Soc Am 135:1775-1788

Freeman LA (2015) Robust performance of marginal Pacific coral reef habitats in future climate scenarios. PLOS ONE 10:e0128875

Freeman SE, Buckingham MJ, Freeman LA, Lammers MO, D'Spain GL (2015) Cross-correlation, triangulation, and curved-wavefront focusing of coral reef sound using a bi-linear hydrophone array. J Acoust Soc Am 137:30-41

Friedlander AM, Brown EK, Jokiel PL, Smith WR, Rodgers KS (2003) Effects of habitat, wave exposure, and marine protected area status on coral reef fish assemblages in the Hawaiian archipelago. Coral Reefs 22:291-305

* Glynn PW (1996) Coral reef bleaching: facts, hypotheses and implications. Glob Change Biol 2:495-509

*Hoegh-Guldberg O (2011) Coral reef ecosystems and anthropogenic climate change. Reg Environ Change 11: 215-227

Hughes TP (1994) Catastrophes, phase shifts, and largescale degradation of a Caribbean coral reef. Science 265: $1547-1551$

Jackson JB, Kirby MX, Berger WH, Bjorndal KA and others (2001) Historical overfishing and the recent collapse of coastal ecosystems. Science 293:629-637

Johnson MW, Everest FA, Young RW (1947) The role of snapping shrimp (Crangon and Synalpheus) in the production of underwater noise in the sea. Biol Bull 93: 122-138

* Johnson MP, Aguilar de Soto N, Madsen PT (2009) Studying the behaviour and sensory ecology of marine mammals using acoustic recording tags: a review. Mar Ecol Prog Ser 395:55-73

Kaplan MB, Mooney TA, Partan J, Solow AR (2015) Coral reef species assemblages are associated with ambient soundscapes. Mar Ecol Prog Ser 533:93-107

Kennedy EV, Holderied MW, Mair JM, Guzman HM, Simpson SD (2010) Spatial patterns in reef-generated noise relate to habitats and communities: evidence from a Panamanian case study. J Exp Mar Biol Ecol 395:85-92
* Langdon C, Takahashi T, Sweeney C, Chipman D and others (2000) Effect of calcium carbonate saturation state on the calcification rate of an experimental coral reef. Global Biogeochem Cycles 14:639-654

Lillis A, Eggleston DB, Bohnenstiehl DR (2014) Estuarine soundscapes: distinct acoustic characteristics of oyster reefs compared to soft-bottom habitats. Mar Ecol Prog Ser 505:1-17

McWilliam JN, Hawkins AD (2013) A comparison of inshore marine soundscapes. J Exp Mar Biol Ecol 446:166-176

*Montgomery JC, Jeffs A, Simpson SD, Meekan M, Tindle C (2006) Sound as an orientation cue for the pelagic larvae of reef fishes and decapod crustaceans. Adv Mar Biol 51: 143-196

Moulton JM (1957) Sound production in the spiny lobster Panulirus argus (Latreille). Biol Bull 113:286-295

* Moulton JM (1960) Swimming sounds and the schooling of fishes. Biol Bull 119:210-223

Nedelec SL, Simpson SD, Holderied M, Radford AN, Lecellier G, Radford C, Lecchini D (2015) Soundscapes and living communities in coral reefs: temporal and spatial variation. Mar Ecol Prog Ser 524:125-135

* Pandolfi JM, Bradbury RH, Sala E, Hughes TP and others (2003) Global trajectories of the long-term decline of coral reef ecosystems. Science 301:955-958

*Pandolfi JM, Jackson JBC, Baron N, Bradbury RH and others (2005) Are U. S. coral reefs on the slippery slope to slime? Science 307:1725-1726

พ Pastorok RA, Bilyard GR (1985) Effects of sewage pollution on coral-reef communities. Mar Ecol Prog Ser 21: 175-189

*Patek SN, Shipp LE, Staaterman ER (2009) The acoustics and acoustic behavior of the California spiny lobster (Panulirus interruptus). J Acoust Soc Am 125:3434-3443

*Plaisance L, Caley MJ, Brainard RE, Knowlton N, Roopnarine $\mathrm{P}$ (2011) The diversity of coral reefs: what are we missing. PLOS ONE 6:e25026

*Piercy JJB, Codling EA, Hill AJ, Smith DJ, Simpson SD (2014) Habitat quality affects sound production and likely distance of detection on coral reefs. Mar Ecol Prog Ser 516:35-47

* Pijanowski BC, Villanueva-Rivera LJ, Dumyahn SL, Farina A and others (2011) Soundscape ecology: the science of sound in the landscape. Bioscience 61:203-216

*Pielou EC (1966) Shannon's formula as a measure of specific diversity: its use and misuse. Am Nat 100:463-465

* Preskitt LB, Vroom PS, Smith CM (2004) A rapid ecological assessment (REA) quantitative survey method for benthic algae using photoquadrats with scuba. Pac Sci 58: 201-209

Radford CA, Jeffs AG, Montgomery JC (2007) Directional swimming behavior by five species of crab postlarvae in response to reef sound. Bull Mar Sci 80:369-378

* Radford CA, Jeffs AG, Tindle CT, Montgomery JC (2008) Temporal patterns in ambient noise of biological origin from a shallow water temperate reef. Oecologia 156: 921-929

* Radford CA, Stanley JA, Tindle CT, Montgomery JC, Jeffs AG (2010) Localised coastal habitats have distinct underwater sound signatures. Mar Ecol Prog Ser 401: 21-29

Richardson WJ, Greene CR Jr, Malme CI, Thomson DH (2013) Marine mammals and noise. Academic Press, San Diego, CA

Rountree RA (2008) Do you hear what I hear? Future techno- 
logical development and needs in passive acoustics underwater observation. Mar Technol Rep 51:40-46

Sebens KP (1994) Biodiversity of coral reefs: What are we losing and why? Am Zool 34:115-133

Simpson SD, Meekan MG, McCauley RD, Jeffs A (2004) Attraction of settlement-stage coral reef fishes to reef noise. Mar Ecol Prog Ser 276:263-268

Simpson SD, Meekan M, Montgomery J, McCauley R, Jeffs A (2005) Homeward sound. Science 308:221

Staaterman E, Paris CB, DeFerrari HA, Mann DA, Rice AN, D'Alessandro EK (2014) Celestial patterns in marine soundscapes. Mar Ecol Prog Ser 508:17-32

Staaterman E, Rice AN, Mann DA, Paris CB (2013) Soundscapes from a tropical Eastern Pacific reef and a Caribbean Sea reef. Coral Reefs 32:553-557

Steneck RS (1983) Escalating herbivory and resulting adaptive trends in calcareous algal crusts. Paleobiology 9: $44-61$

Editorial responsibility: Charles Peterson, Morehead City, North Carolina, USA
Sueur J, Pavoine S, Hamerlynck O, Duvail S (2008) Rapid acoustic survey for biodiversity appraisal. PLOS ONE 3: e4065

Tavolga WN (1964) Sonic characteristics and mechanisms in marine fishes. In: Tavolga WN (ed) Marine bio-acoustics, Symp Proc, 11-13 April 1963, Bimini, Bahamas. Pergamon Press, New York, NY, p 195-211

Tebben J, Motti CA, Siboni N, Tapiolas DM and others (2015) Chemical mediation of coral larval settlement by crustose coralline algae. Sci Rep 5:10803

Tricas TC, Boyle KS (2014) Acoustic behaviors in Hawaiian coral reef fish communities. Mar Ecol Prog Ser 511:1-16

*Vermeij MJ, Marhaver KL, Huijbers CM, Nagelkerken I, Simpson SD (2010) Coral larvae move toward reef sounds. PLOS ONE 5:e10660

* Zuur AF, Ieno EN, Elphick CS (2010) A protocol for data exploration to avoid common statistical problems. Methods Ecol Evol 1:3-14

Submitted: June 3, 2016; Accepted: October 17, 2016

Proofs received from author(s): December 12, 2016 